\title{
Notas biográficas de los autores
}

Stanley Brandes es profesor de Antropología en la Universidad de California, Berkeley, en donde consiguió su doctorado en 1971. Desde entonces ha realizado trabajo de campo en las provincias españolas de Ávila, Jaén, Barcelona y Cáceres, además del estado de Michoacán, México, la Ciudad de México y el departamento guatemalteco de Suchitepéquez. Es autor de seis libros y numerosos artículos y capítulos que tratan de cuestiones de religión popular, alimentación, género, folklore, migración, antropología visual y ciclos de vida, entre otros temas. Su libro más reciente es Estar sobrio en la ciudad de México (Plaza y Janés 2004).

Jesús M. de Miguel es catedrático de Sociología, en el Departamento de Sociología de la Universidad de Barcelona y Catedrático Príncipe de Asturias en la Universidad de Georgetown. Doctor en Ciencia Política por la Universidad Complutense, y $\mathrm{PhD}$ en sociología por la Universuidad de Yale. Ha sido profesor en la universidad de California Berkeley e investigador en Stanford University, University of California San Diego, University of Arizona, University of Adelaide (Australia), y Universidad de Hosei (Tokio, Japón). Ha sido fellow de la Fundación Rockefeller en el Bellagio Center. Ha publicado una cincuentena de libros y ciento cincuenta artículos profesionales en español y en inglés. Entre los libros destacan Sociology in Spain (Sage 1979), Politicas de población (con Juan Díez Nicolás, en Fontanella 1985), El mito de la sociedad organizada (Península 1991), Estructura y cambio social en España (Alianza Editorial 1998). Es coautor del libro Excelencia: Calidad de las universidades españolas (CIS 2001), y Sociología Visual (2002).

Philippe Lejeune enseña literatura francesa en la Universidad París-Nord (Villetaneuse). Es cofundador de l'Association pour l'autobiographie (APA), un ambicioso proyecto de inventario de todo cuanto se relaciona con la literatura del yo y los relatos e historias de vida, publicadas o no. Es autor de algunos textos seminales y de obligada consulta como: L'Autobiographie en France (1971); Lire Leiris. Autobiographie et langage (1975); el famoso Le pacte autobiographique (1975), único libro traducido al español; Je est un autre. L'autobiograhie, de la litterature aux médias (1980); Moi aussi (1986); Le moi des demoiselles. Enquête sur le journal de jeune fille (1993); Les Brouillons de soi (1998); Pour l'autobiographie. Chroniques (1998) y en colaboración Cher cahier... (1989) y Un journal a soi. Histoire d'une pratique (2003). Ha colaborado asiduamente en el Boletín de la Unidad de Estudios Biográficos (1996-2001),donde se le puede leer en castellano y también ha sido traducido en la revista Historia, Antropología y Fuentes Orales. 
Álvaro Pazos. Doctor en Sociología (Antropología Social) por la Universidad Complutense de Madrid. Profesor de Antropología Social en la Universidad Autónoma de Madrid. Ha trabajado el tema del cuerpo como objeto de investigación en ciencias sociales, las representaciones sociales y la construcción social del cuerpo. Asimismo, trabaja los problemas derivados del estudio de la subjetividad en sociología y antropología social. Sobre ambos temas ha escrito diversos artículos. Es coautor del libro Los niños españoles en la URSS (1937-1997): narración y memoria (2001).

Renato Rosaldo ha sido Mellon Prrofessor of Interdisciplinary Studies en la Universidad de Stanford y miembro del American Academy of Arts and Sciences. Actualmente es profesor en la Universidad de Nueva York. Entre sus muchas publicaciones destacan Ilongot Headhunting, 1883-1974: A Study in Society and History (1980) y Culture and Truth: The Remaking of Social Analysis (1989), traducida en Grijalbo (1992). Recientemente ha venido trabajando sobre la ciudadanía cultural de los chicanos, como se puede apreciar en su contribución a Latino Cultural Citizenship: Claming Identity, Sapce, and Rigth (1997), W. Flores \& R. Benmayor (Edit.)

José Manuel Sobral es licenciado en Historia y doctor en Antropología. Ha realizado investigaciones sobre la sociedad rural portuguesa y en particular sobre familia, parentesco, estratificación social, religión, poder y resistencia. Posteriormente se ha interesado en el estudio de la memoria social, nacionalismo en Portugal desde una perspectiva comparada y representaciones de la identidad nacional en los siglos XIX y XX. Ha sido profesor asistente de Historia en la Faculdad de Letras de la Universidad de Lisboa y actualmente es investigador en el Instituto de Ciências Sociais de la Universidad de Lisboa. Entre sus publicaciones destacan Trajectos - $o$ Passado e o Presente na Vida de uma Freguesia da Beira-(Lisboa, Imprensa de Ciências Sociais, 1999) "A Formação das Nações e o Nacionalismo: os Paradigmas Explicativos e o Caso Português" (Análise Social, nº165, Invierno de 2003) y "O Norte e o Sul, a Raça, a Nação (Representações da Identidade Nacional Portuguesa, séculos XIX-XX)", (Análise Social no 171, Julio de 2004). Actualmente es Presidente de la Dirección de la Associação Portuguesa de Antropologia (APA).

Bernard Lahire es Profesor de sociología en L'Ecole Normale Supérieure de Lettres et Sciences Humaines y Director del Grupo de investigación sobre la Socialización (CNRS/Université Lyon). Entre otras obras, es autor de Culture écrite et inégalités scolaires (PUL, Lyon, 1993), Tableaux de familles. Heurs et malheurs scolaires en milieux populaires (Gallimard/Seuil, 1995), L'Homme pluriel. Les ressorts de l'action (Nathan, 1998 ; traducido al castellano por Edicions Bellaterra), 
Portraits sociologiques. Dispositions et variations individuelles (Nathan, 2002) y La culture des individus. Dissonances culturelles et distinction de soi (La Découverte, 2004).

Renaud Dulong es director de investigación en el CNRS, miembro del Centro de Estudios sobre Movimientos Sociales en la Ecole des Hautes Etudes en Sciences Sociales (París). Sus investigaciones apuntan a la elaboración de una sociología de la factualidad, un análisis pragmático de los procesos mediante los cuales, en contextos formales o informales, se presiente un acontecimiento pasado. Tras un estudio sobre el testimonio ocular y la dirección de una investigación sobre la confesión, trabaja actualmente sobre la epistemología de las huellas.

Marie José Devillard es Profesora Titular de la Universidad Complutense de Madrid. En la actualidad está especialmente interesada por las dimensiones analíticas de la construcción de la persona, tema al que ha contribuido con varias investigaciones y enfoques. Es autora de De 'lo mio'a 'lo de nadie'. Individualismo, colectivismo agrario y vida cotidiana (1993), y coautora de distintos libros relacionados con el tema: La voz callada. Aproximación antropológica al enfermo de artritis reumatoide (1991), Los niños españoles de la URSS (1937-1997): narración y memoria (2001) y Los últimos mineros (2002).

Ignasi Terradas Saborit ha publicado sobre colonias industriales [(1994) $\mathrm{La}$ qüestió de les colònies industrials. Manresa, Centre d'Estudis del Bages]; el sentido capitalista del suicidio [(1992) Eliza Kendall. Bellaterra, Publicacions de la UAB]; la ética en la historia de la teoría social [(1988) Mal natural, mal social. Barcelona, Barcanova]; los complejos rurales tradicionales de Cataluña [(1984) El món històric de les masies.Barcelona, Curial; (2000) El Cavaller de Vidrà. Barcelona, Publicacions de l'Abadia de Montserrat]; los rituales laicos, cristianos y deístas durante la Revolución francesa [(1990) Revolución y religiosidad. Valencia, Edicions Alfons el Magnànim]; el ritual funerario de los Toda [(1995) Requiem Toda. Barcelona, Publicacions de la UB].

Guillermo De la Peña es un eminente investigador del CIESAS (Centro de Investigaciones y Estudios Superiores en Antropología Social) en Guadalajara, Méjico. Realizó estudios de Doctorado en la Universidad de Manchester y ha sido profesor visitante en diversas universidades, entre otras en la Universidad de Chicago. Entre su extensa obra destaca A Legacy of promises ( en español Herederos de promesas. Agricultura, politica y ritual en los altos de Morelos) y también como editior en Ensayos sobre el sur de Jalisco y cambio regional, mercado de trabajo y vida obrera en Jalisco. 
Regina Martinez Casas es Doctora en Ciencias Antropológicas por la Universidad Autonoma Metropolitana -- Iztapalapa,México. Ha trabajado sobre las culturas indigenas en la ciudad y concretamente sobre un grupo Otomí en Guadalajara. Fruto de ello es la investigación titulada: Una cara indigena de Guadalajara: la resignificación de la cultura Otomí en la ciudad. 